2018

\title{
Admission Requirements and Practices in Entry- Level Occupational Therapy Programs
}

Patricia Bowyer

Texas Woman's University, Houston

Cynthia Tiongco

Texas Tech University Health Sciences Center

L. Kaye Rubio

Texas Woman's University, Houston \& HCA Palms of Pasadena Hospital

Judy Liu

Texas Woman's University, Houston

Sandra M. Whisner

Texas Tech University Health Sciences Center

Follow this and additional works at: https://encompass.eku.edu/jote

Part of the Medical Education Commons, and the Occupational Therapy Commons

\section{Recommended Citation}

Bowyer, P., Tiongco, C., Rubio, L., Liu, J., \& Whisner, S. M. (2018). Admission Requirements and Practices in Entry-Level

Occupational Therapy Programs. Journal of Occupational Therapy Education, 2 (3). https://doi.org/10.26681/jote.2018.020301

This Original Research is brought to you for free and open access by Encompass. It has been accepted for inclusion in Journal of Occupational Therapy Education by an authorized editor of Encompass. For more information, please contact Linda.Sizemore@eku.edu. 


\title{
Admission Requirements and Practices in Entry-Level Occupational Therapy Programs
}

\begin{abstract}
When establishing admission processes for entry-level doctoral programs, admission requirements for masterlevel programs provide a comparison for consideration. The purpose of this study was to provide information about admission practices for graduate-level occupational therapy programs. The three aims included: 1) to describe admission requirements of a sample of entry-level master's programs; 2) to examine the relationship between attrition and admission requirements for the sample; and 3) to provide a summary of admission requirements used by entry-level master and doctoral programs in the United States. Results of the study provided a synthesis of information about admission requirements that included programs' minimum preadmission grade point average, Graduate Record Examination (GRE) requirements, and interview processes (e.g., format, time, personnel). A review of the websites for 172 entry-level master's and doctoral programs across the United States provided a comprehensive description of national admission requirements. Results of a survey of 31 master's level programs provided information on student demographics (e.g., race/ethnicity, gender), admission requirements, and attrition information for the cohorts admitted in a single year. Survey results also examined the relationship between attrition and admission requirements. Educational programs have opportunities, responsibilities, and challenges associated with the selection of the most qualified applicants to meet academic and professional behavior standards. Periodic examination of admission processes within and across occupational therapy education programs is important for the integrity of the profession.
\end{abstract}

\section{Keywords}

Admission criteria, grade point average, interview, health professional education, GRE

\section{Creative Commons License}

(ब) (1) $(9)$

This work is licensed under a Creative Commons Attribution-Noncommercial-No Derivative Works 4.0 License. 


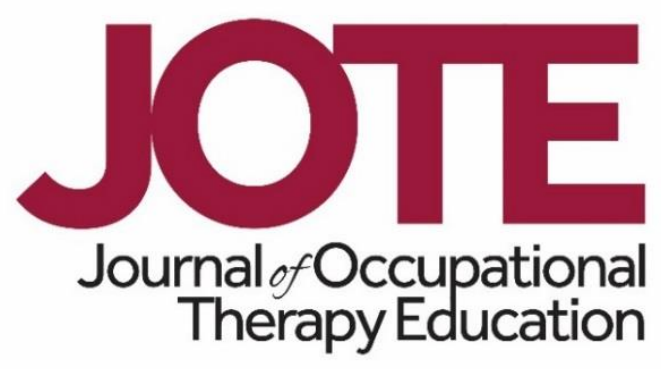

Volume 2, Issue 3

\title{
Admission Requirements and Practices in Entry-Level \\ Occupational Therapy Programs
}

\author{
Patricia Bowyer, EdD, M.S., OTR, FAOTA ${ }^{1}$, Cynthia Tiongco, OTR/L ${ }^{1,2}$,
}

L. Kaye Rubio, OTR/L, MHS, CLT ${ }^{1}$, Judy Liu, OTR ${ }^{3}$, and Sandra Whisner, OTR, PhD ${ }^{2}$

Texas Woman's University ${ }^{1}$

Texas Tech University Health Sciences Center ${ }^{2}$

PRN Desert Rehabilitation ${ }^{3}$

United States

\begin{abstract}
When establishing admission processes for entry-level doctoral programs, admission requirements for master-level programs provide a comparison for consideration. The purpose of this study was to provide information about admission practices for graduate-level occupational therapy programs. The three aims included: 1) to describe admission requirements of a sample of entry-level master's programs; 2 ) to examine the relationship between attrition and admission requirements for the sample; and 3) to provide a summary of admission requirements used by entry-level master and doctoral programs in the United States. Results of the study provided a synthesis of information about admission requirements that included programs' minimum pre-admission grade point average, Graduate Record Examination (GRE) requirements, and interview processes (e.g., format, time, personnel). A review of the websites for 172 entry-level master's and doctoral programs across the United States provided a comprehensive description of national admission requirements. Results of a survey of 31 master's level programs provided information on student demographics (e.g., race/ethnicity, gender), admission requirements, and attrition information for the cohorts admitted in a single year. Survey results also examined the relationship between attrition and admission requirements. Educational programs have opportunities, responsibilities, and challenges associated with the selection of the most qualified applicants to meet academic and professional behavior standards. Periodic examination of admission processes within and across occupational therapy education programs is important for the integrity of the profession.
\end{abstract}




\section{INTRODUCTION}

The purpose of professional education is to admit and educate a sufficient number of students who meet minimal theoretical knowledge and skill competencies to practice a profession (Mayhew \& Ford, 1974, as cited in American Occupational Therapy Association (AOTA), 2007). Programs establish admission criteria in an effort to select applicants who will be successful in graduate academic programs and fieldwork/clinical requirements, as well as those with personal characteristics that will lead to successful occupational therapy careers (Fisher, 2000; Haber et al., 2015; Kirchner, Stone, \& Holm, 2001; Lysaght, Donnelly, \& Villeneuve, 2009).

The Accreditation Council for Occupational Therapy Education (ACOTE) mandated that by 2027 an entry-level doctoral degree will be required for occupational therapists to enter the profession (AOTA, 2017). Currently, the majority of occupational therapy programs are at the master's degree level (AOTA, n.d.). Many of these programs are looking for resources to plan the transition to an entry-level doctorate. Examination of admissions criteria and processes is a necessary consideration for the selection of students who will be most successful in meeting the increased demands of a doctoral program. A description of admission requirements and practices for both master's and doctoral occupational therapy programs is beneficial information during this transition process.

\section{LITERATURE REVIEW}

A review of the literature reveals a lack of studies that provide a comprehensive description of admission requirements for both master and doctoral occupational therapy programs in the United States. The most recent national review of admission methods was completed for 2001-2002, which identified the most common admission requirements among 78 accredited occupational therapy programs (Auriemma, 2007). These included undergraduate grade point average (UGPA), letters of recommendation, prerequisite GPA, volunteer experience, spontaneous writing sample, and standardized tests. This is consistent with the AOTA Commission on Education's admission requirements for consideration that also included interview, community service/work experience and prerequisite classes/degree (AOTA, 2016). There is also literature that has examined the relationship between academic admission factors and student performance on fieldwork (e.g., Haber et al., 2015; Kirchner et al., 2001; Lysaght et al., 2009). Admission requirements can be grouped by cognitive and non-cognitive admission factors.

\section{Cognitive Admission Factors}

Common cognitive admission factors include pre-admission GPA and scores on the Graduate Record Examination (GRE). Pre-admission GPA (P-GPA) may include the average of all courses taken prior to application (cumulative GPA); the average of all courses taken in the applicant's undergraduate program (undergraduate grade point average [UGPA]); the average GPA of required courses (prerequisite GPA); or the average GPA of the prerequisite science courses (science GPA). Evidence across health profession disciplines supports the predictive value of pre-admission GPA in professional curricula GPA (Halberstam \& Redstone, 2005; Kim et al., 2016; Siu \& 
Reiter, 2009). The GRE has three subtests as part of the general test: the Verbal Reasoning section, the Quantitative Reasoning section, and the Analytical Writing section (Educational Testing Service, 2016). Scores on the GRE, along with preadmission GPA, have been shown to correlate with occupational therapy program GPA (Kirchner et al., 2001; Lysaght et al., 2009). There is some evidence that suggests the use of the GRE in admission processes decreases the diversity of the applicant pool (e.g. Wolf, 2014). Other literature found that increased minority representation was not a direct result of lack of a GRE requirement (Cahn, 2014).

Cognitive admission factors have also been shown to have a significant relationship with the clinical performance of health profession students. Kreiter and Kreiter (2007) found UGPA to have a positive predictive value with the clinical skills of medical students. Results of a study of 108 occupational therapy students in an entry-level master's program found a significant relationship between Level II fieldwork evaluation scores and pre-admission cumulative GPA and the written portion of the GRE (Haber et al., 2015). Scores on the GRE have demonstrated predictive value across allied health disciplines for estimating student clinical performance (Baggs, Barnett, \& McCullough, 2015), success on licensure exams (Hollman et al., 2008), and academic risk (Utzman, Riddle, \& Jewell, 2007).

\section{Non-Cognitive Admission Factors}

Non-cognitive admission factors include items such as interviews and personal essays. Non-cognitive variables are thought to influence future performance in interpersonal situations, such as patient interaction and interprofessional relations. Overall, literature indicates limited prediction of academic and professional success based on personal interviews during admission to healthcare programs (Goho \& Blackman, 2006; Siu \& Reiter, 2009). Dahlin, Söderberg, Holm, Nilsson, and Farnebo (2012) found interviews to have minimal predictive value in identifying medical students at risk of poor communication skills, but failed to identify students' capacity for success in academic or clinical performance. Despite the evidence, interviews often have been cited as a method to measure non-cognitive variables, such as communication and interpersonal skills, in health professions literature (Dahlin et al., 2012; Eva, Rosenfeld, Reiter, \& Norman, 2004; Goho \& Blackman, 2006; Lyons, Mackenzie, Bore, \& Powis, 2006).

In summary, a goal of the admission process is to select students who will be most successful in meeting the demands of occupational therapy education and practice. Research substantiates the inclusion of cognitive factors (i.e., pre-admission GPA, GRE) as admission requirements. Personal interviews remain a common component of the admission process despite very limited and inconclusive evidence with regard to this non-cognitive factor. The majority of studies have investigated the predictive nature of admission factors on academic and clinical performance. None of these studies included attrition as a predictive outcome of admission factors-likely due to the high retention rates of occupational therapy programs. As such, the relationship between attrition and admission factors remains to be examined. 


\section{METHODS}

\section{Purpose}

The overarching aim of the study was to provide information about admission requirements and practices for occupational therapy programs that can be useful for evaluating admission processes. The primary purpose was to describe admission requirements and practices of a sample of entry-level master of occupational therapy programs. A second purpose was to examine the relationship between attrition and admission requirements for the sample of programs. A final purpose was to provide a summary of admission requirements used by graduate, entry-level master and doctoral level occupational therapy programs across the United States.

\section{Methodology}

The Institutional Review Board of the primary author's institution approved this research study. Researchers recruited survey participants who were program directors of accredited entry-level master and doctoral occupational therapy programs from a mailing list that was purchased from AOTA. Participants completed an online survey in 2015 that requested information about the cohort of students who matriculated in 2012. This cohort had recently completed both academic and clinical fieldwork requirements for graduation at the time of the 2015 survey, allowing for complete attrition information to be reported. The survey link was sent five times, with approximately two weeks between each email.

Survey. The research team designed the survey in SurveyMonkey (SurveyMonkey Inc., n.d.). The survey contained nineteen close-ended questions about student demographics, admission process, and attrition information. Admission process specifically looked at three common admission requirements: undergraduate GPA, GRE scores, and interview practices. These three admission requirements were selected by the research team based on the literature related to health profession admission data, as well as occupational-therapy specific literature. For example, the last comprehensive survey of occupational therapy admission information was completed in 2007 (Auriemma, 2007), and included UGPA as a factor. Additionally, UGPA was selected over pre-requisite or pre-admission GPA as the team determined this GPA variable was most likely to be consistent across programs.

Data was described using frequencies, modes, and means within the analysis features of SurveyMonkey. Next, Statistical Package for the Social Sciences (SPSS), version 22 (IBM Corp, 2013) was used to explore the associations between select variables specifically related to attrition.

Website review. In addition to the survey, researchers completed a comprehensive national review of admission requirements of accredited entry-level occupational therapy programs. Programs were identified via the "Find a School" page on the AOTA website (AOTA, n.d.). The researchers reviewed the websites of all fully accredited entry-level occupational therapy programs to collect admission requirement information. This website review process occurred during July of 2017. Programs were excluded if: 
(1) the program was not fully accredited at the time of the review, (2) the program was fully accredited as a master's level program but transitioning to a doctoral-level program and no longer had master's level admission requirements on the website, and (3) the program was a five-year program with primarily college entrance admission requirements, such as high school grade point average and college entrance exam scores (e.g., SAT). Additionally, programs with multiple campus locations that had a single admission process were included as one program.

\section{RESULTS}

The results first present information about admission requirements and practices of occupational therapy programs gathered by the survey. Next, data obtained from the website review is summarized.

\section{Survey Results}

Of the 165 programs on the AOTA mailing list, the survey link was sent to 155 program directors (two program directors were not listed, three did not have an email listed, and five program directors were the program director of two campuses). In total, thirty-one responses were received (a $20 \%$ response rate).

Demographics. Survey respondents were representative of programs across all areas of the continental United States. All 31 respondents reported admission information for master's level programs. No responses were received for doctoral level occupational therapy programs. Most of the respondents were from occupational therapy programs in the Midwest $(38.7 \%, n=12)$ and represented public universities $(67.7 \%, n=21)$. Table 1 presents information about the region and type of institution for each of the responding programs.

Table 1

Demographic Information on Occupational Therapy Programs ( $n=31)$

\begin{tabular}{|c|c|c|}
\hline Demographic & Descriptor & Number of Programs, $\mathrm{n}(\%)$ \\
\hline \multirow[t]{5}{*}{ Region } & Midwest & $12(38.7)$ \\
\hline & South & $8(25.8)$ \\
\hline & Northeast & $6(19.4)$ \\
\hline & Northwest & $3(9.7)$ \\
\hline & Southwest & $2(6.5)$ \\
\hline \multirow{2}{*}{$\begin{array}{l}\text { Public vs Private } \\
\text { Institution }\end{array}$} & Public & $21(67.7)$ \\
\hline & Private & $10(32.3)$ \\
\hline
\end{tabular}

Table 2 presents the average number of applicants reported by 30 of the 31 programs $(96.8 \%)$. The average number of applicants to each program was 263 , with a low applicant pool number of 75 and a high of 600 (median $=240$; mode $=300$ ). 
Table 2

Applicants for 2012 Cohort ( $n=30)$

\begin{tabular}{|l|l|}
\hline $\begin{array}{l}\text { Number of } \\
\text { Applicants }\end{array}$ & Number of Programs Reporting, $n(\%)$ \\
\hline $1-100$ & $6(20)$ \\
\hline $101-200$ & $7(23)$ \\
\hline $201-300$ & $3(10)$ \\
\hline $301-400$ & $9(30)$ \\
\hline $401-500$ & $3(10)$ \\
\hline$>500$ & $2(7)$ \\
\hline
\end{tabular}

Notes. One program did not provide information on the size of the applicant pool.

Respondents reported information on the demographics of the students who had recently completed both didactic and fieldwork components of occupational therapy education. The majority of students across all programs were female. Eighty-four percent $(n=26)$ of the programs reported that male students comprised between zero and 20 percent of the cohort, while $16 \%(n=5)$ reported male students as 21 to 40 percent of the cohort.

Table 3 presents the number of programs according to the percentage range of students in the cohort by race and ethnicity. Fifty-eight percent $(n=18)$ of the respondents indicated that between 81 and 100 percent of the cohort were white/nonHispanic. Whereas, students identifying as Hispanic or Asian/Pacific Islander accounted for $20 \%$ or less of the cohort for 28 of the 31 programs.

Table 3

Race/Ethnicity of 2012 Cohort ( $n=31)$

\begin{tabular}{|l|c|c|c|c|c|}
\hline & \multicolumn{5}{|c|}{$\begin{array}{c}\text { Number of programs with listed percentage } \\
\text { of race/ethnicity, } \mathrm{n}(\%)\end{array}$} \\
\hline \multicolumn{1}{|c|}{ Race/Ethnicity } & $0-20 \%$ & $21-40 \%$ & $41-60 \%$ & $61-80 \%$ & $81-100 \%$ \\
\hline African-American/Black & $26(83.9)$ & $0(0)$ & $0(0)$ & $4(12.9)$ & $0(0)$ \\
\hline Asian/Pacific Islander & $28(90.3)$ & $1(3.2)$ & $0(0)$ & $0(0)$ & $0(0)$ \\
\hline Hispanic & $28(90.3)$ & $2(6.5)$ & $1(3.2)$ & $0(0)$ & $0(0)$ \\
\hline $\begin{array}{l}\text { Native American/ Native } \\
\text { Alaskan }\end{array}$ & $25(80.7)$ & $1(3.2)$ & $0(0)$ & $0(0)$ & $0(0)$ \\
\hline White/Non Hispanic & $3(9.7)$ & $4(12.9)$ & $1(3.2)$ & $5(16.1)$ & $18(58.1)$ \\
\hline
\end{tabular}


Admission process. One program did not provide information regarding the admission process and was excluded from further analysis. Thirty program respondents $(96.8 \%$ of total survey respondents) reported an average admission rate of $17.2 \%$, with the lowest admission rate being $5.2 \%$ and the highest being $38.8 \%$. An average of 34 students were admitted, with a minimum class size of 14 and a maximum of 56 (median $=33$; mode $=32$ ). Quartiles were used to create class-size ranges. Programs in the first quartile had class sizes that ranged between 14 and 28 students (mean=21); programs in the second quartile ranged from 30 or 31 students (mean=30.3); programs in the third quartile ranged from 32 to 36 students (mean=33.7); and programs in the fourth quartile ranged from 40 to 56 students (mean=47.4).

Table 4 presents the information from 30 programs about the inclusion of the following admission requirements: undergraduate grade point average (UGPA), interviews, and Graduate Record Examination (GRE) scores. Fourteen programs (46.7\%) reported the use of the GRE as an admission tool. Eleven of the programs (36.7\%) accepted a total GRE score. Ten programs (33.3\%) accepted both the verbal GRE score and the quantitative GRE scores. UGPA was used as a requirement for master of occupational therapy program admission in 25 (83.3\%) programs. Twenty-seven programs (90\%) provided average UGPA information. The average UGPA for the admitted cohort of those programs was a 3.46 out of a 4.00 scale (high $=3.85$; low $=3.00$; mode $=3.50$; median $=3.50$ ).

Table 4

Admission Requirements of Survey Respondents $(n=30)$

\begin{tabular}{|l|l|l|}
\hline & Yes, $\mathrm{n}(\%)$ & No, $\mathrm{n}(\%)$ \\
\hline GRE & $14(46.7)$ & $16(53.3)$ \\
\hline Interviews & $20(66.7)$ & $10(33.3)$ \\
\hline UGPA & $25(83.3)$ & $5(16.7)$ \\
\hline
\end{tabular}

Sixty-seven percent $(n=20)$ of responding programs utilized interviews as a part of the admission process. Interview format for those 20 programs varied. Eight programs $(40 \%)$ indicated the use of a panel interview with one applicant, while two programs $(10 \%)$ indicated the use of a panel interview with multiple interviewees. A oneinterviewer to one-applicant interview was used in six (30\%) of the programs, and a multi-mini interview was used in four $(20 \%)$ of responding programs. In addition to format, Table 5 presents the reported interview content of the 20 reporting programs. 
Table 5

Interview descriptors $(n=20)$

\begin{tabular}{|l|c|}
\hline Description of Interview & Respondents (n, \%) \\
\hline Same amount of time for each interview & $19(95)$ \\
\hline Same questions & $18(90)$ \\
\hline Give a problem to solve & $17(85)$ \\
\hline Respond to a question in writing & $17(85)$ \\
\hline More than one interview & $15(75)$ \\
\hline Random questions asked from a predetermined list & $15(75)$ \\
\hline Subjective report at end & $15(75)$ \\
\hline Spontaneous questioning & $14(70)$ \\
\hline
\end{tabular}

Notes. More than one category could be selected.

Occupational therapy faculty members conducted interviews in all twenty $(100 \%)$ programs that reported completing interviews. Additional personnel involved in interviews included current students $(35 \%, n=7)$, program alumni $(35 \%, n=7)$, clinicians $(30 \%, n=6)$, other faculty $(25 \%, n=5)$, and graduate admissions office staff $(15 \%, n=3)$.

Of the 20 programs that used interviews, 11 programs (55\%) reported the amount of time each applicant spent in the interview process. Applicant interviews were reported to last between 15 and 60 minutes, with $45-60$ minutes the most common response $(36.4 \%, n=4)$.

Fifty-five percent $(n=11)$ of the 20 programs that interviewed applicants reported training and overall preparation time for interviews. Respondents reported training times that ranged in duration from $30-45$ minutes $(36.4 \%, n=4)$ up to more than two hours $(36.4 \%$, $\mathrm{n}=4$ ) and different training sources that included an admissions committee member $(36.4 \%, n=4)$, faculty member $(18.2 \%, n=2)$, human resources employee $(18.2 \%, n=2)$, the program director $(9.1 \%, n=1)$, or associate director $(9,1 \%, n=1)$. Table 6 presents the total amount of time spent by the admission committee preparing for interviews. Both faculty and support staff spent time preparing for interviews, with over $50 \%$ of support staff and $36 \%$ of faculty spending more than 20 hours of preparation.

Table 6

Number of Hours Spent Preparing for Interviews $(n=11)$

\begin{tabular}{|c|c|c|}
\hline & \multicolumn{2}{|c|}{ Admission Committee Members } \\
\hline Number of hours & Faculty $\mathrm{n}(\%)$ & Support Staff $\mathrm{n}(\%)$ \\
\hline $3-10$ & $6(54.6)$ & $3(27.3)$ \\
\hline $11-20$ & $1(9.1)$ & $1(9.1)$ \\
\hline $21-30$ & $1(9.1)$ & $2(6.7)$ \\
\hline Greater than 31 & $3(27.3)$ & $5(45.5)$ \\
\hline
\end{tabular}


Twenty-nine of the thirty-one program respondents (93.6\%) provided information about student attrition from the cohort. Student attrition was measured in the survey by the reasons that students left the occupational therapy educational program before finishing the course of study. Numbers of students who left the program were not measured, rather the survey requested the reason(s) for attrition. Eighty-three percent $(n=24)$ of the respondents reported attrition that occurred for the cohort. Table 7 presents reported reasons for student attrition. Failure to meet academic standards within the academic program was cited as the most common reason for attrition $(62.1 \%, n=18)$. Five programs (17.2\%) reported no attrition from the class of 2012.

Table 7

Reasons for Attrition ( $n=29)$

\begin{tabular}{|l|c|}
\hline Reason for Attrition & Reporting programs, $\mathrm{n}(\%)$ \\
\hline Failure to meet academic standards & $18(62.1)$ \\
\hline Student - serious illness or death & $8(25.8)$ \\
\hline Change to part-time program & $7(24.1)$ \\
\hline Family obligations (illness, death, pregnancy) & $6(20.7)$ \\
\hline Quit for career change & $5(17.2)$ \\
\hline No attrition & $5(17.2)$ \\
\hline Unknown reason & $3(10.3)$ \\
\hline
\end{tabular}

Notes. More than one category could be selected.

Relationship of admission information and attrition. Researchers examined the relationship between admission information and attrition reported by survey respondents. Crosstabulation using Pearson's Chi-square test was used to explore the relationship of attrition with class size, interview (yes/no), interview (format), UGPA (yes/no), UGPA (cohort average) and GRE (yes/no) respectively.

Class size was the only variable that had a statistically significant correlation with attrition. Table 8 presents the results of the statistical analysis that examined the relationship between attrition and class size. Results revealed a statistically significant correlation between class size and attrition occurrence $\left(x^{2}=10.68, d f=3, p=0.014\right)$, with increased class size demonstrating an increased risk for student attrition. 
Table 8

The Relationship of Class Size and Attrition

\begin{tabular}{|c|c|c|c|c|c|}
\hline & Number of & Attrition & currence & & \\
\hline & & $\begin{array}{c}\text { Yes } \\
\mathrm{n}(\%)\end{array}$ & $\begin{array}{c}\text { No } \\
\mathrm{n}(\%) \\
\end{array}$ & $x^{2}$ & $\mathrm{p}$ \\
\hline Class Size & & & & 10.68 & .014 \\
\hline$<29$ & 7 & $3(42.9)$ & $4(57.1)$ & & \\
\hline $29-31$ & 4 & $4(100.0)$ & $0(0.0)$ & & \\
\hline $32-39$ & 10 & $9(90.0)$ & $1(10.0)$ & & \\
\hline$>40$ & 8 & $8(100.0)$ & $0(0.0)$ & & \\
\hline $\begin{array}{l}\text { Total } \\
\text { Number of } \\
\text { Programs }\end{array}$ & 29 & 24 & 5 & & \\
\hline
\end{tabular}

Notes. Five cells (62.5\%) have expected count less than 5.

No statistically significant correlation was found between attrition and the other admission criterion that included interview (yes/no) $\left(x^{2}=0.34, \mathrm{df}=1, p=0.558\right)$, interview format $\left(x^{2}=5.16, d f=3, p=0.161\right)$, UGPA (yes/no) $\left(x^{2}=1.26, d f=1, p=0.262\right)$, average UGPA (i.e., only programs who reported cohort average UGPA) $\left(X^{2}=10.43, \mathrm{df}=11\right.$, $p=0.492)$, and GRE (yes/no) $\left(x^{2}=0.56, d f=1, p=0.453\right)$.

\section{Website Review}

A review of admission requirements published on program websites was completed to supplement the survey findings and provide a more comprehensive understanding of the trends for admission requirements.

The websites of 169 accredited entry-level master's programs and 16 accredited entrylevel doctoral programs were reviewed for published admission requirements. Thirteen master's level programs $(7.7 \%)$ did not have sufficient information about admission requirements on their website and were not included in the final review. Table 9 provides a summary of admission requirements based on the 2017 website review. Findings revealed that the majority of entry-level master's and doctoral programs require a minimum pre-admission GPA (P-GPA), GRE scores, a personal statement and/or essay, letters of reference, observation/volunteer hours, and interviews. 
Table 9

Admission Requirements for Entry-Level OT Programs (master's level $n=156$; doctoral level $n=16$ )

\begin{tabular}{|l|c|c|}
\hline $\begin{array}{l}\text { Admission } \\
\text { Requirement }\end{array}$ & $\begin{array}{l}\text { Master's Level Programs } \\
\text { Requiring Criterion } \mathrm{n}(\%)\end{array}$ & $\begin{array}{c}\text { Doctoral Level Programs } \\
\text { Requiring Criterion } \mathrm{n}(\%)\end{array}$ \\
\hline Minimum P-GPA & $155(99.4)$ & $16(100.0)$ \\
\hline $\begin{array}{l}\text { Letters of } \\
\text { recommendation }\end{array}$ & $127(81.4)$ & $14(87.5)$ \\
\hline Observation hours & $126(80.8)$ & $13(81.3)$ \\
\hline Personal Essay & $114(73.1)$ & $11(68.8)$ \\
\hline OTCAS & $95(60.9)$ & $16(100.0)$ \\
\hline GRE & $84(53.9)$ & $11(68.8)$ \\
\hline Interview & $78(50.0)$ & $10(62.5)$ \\
\hline
\end{tabular}

Notes. Information was obtained in July of 2017 from program websites.

The admission requirements for entry-level master's and doctoral programs were similar for all admission requirements. The following sections provide additional information about each of the admission requirements.

Minimum preadmission GPA. The majority of programs (master's, 99.4\%, $\mathrm{n}=155$; doctoral, $100 \%, n=16$ ) required a minimum $P$-GPA. The average minimum required $P$ GPA for master's level was a 3.0 (mode=3.0, $\min =2.0$, $\max =3.5)$, with $127(81.9 \%)$ programs requiring a 3.0. The average minimum P-GPA for doctoral programs was a 3.0 (mode=3.0, $\min =2.0$, $\max =3.5)$ with $12(75 \%)$ doctoral level programs requiring a 3.0.

Letters of recommendation. The majority of programs (master's, $81.4 \%, \mathrm{n}=127$; doctoral, $87.5 \%, n=14$ ) required letters of recommendation. The average number of required letters for master's level programs was 2.6 ( $\operatorname{mode}=3$, $\min =1$, $\max =3$ ), as compared to an average of 2.7 letters $(\operatorname{mode}=3, \min =2, \max =3$ ) for doctoral level programs.

Observation. The majority of programs (master's, $80.8 \%, n=126$; doctoral, $81.3 \%$, $\mathrm{n}=13$ ) required volunteer, work, or observation experiences. Most programs specified a minimum number of required hours with an average for master's level programs of 39.4 ( $\operatorname{mode}=40, \min =8, \max =100$ ). The average number of required hours for doctoral level programs was $44.2(\operatorname{mode}=40, \min =20, \max =80)$.

Essay or personal statement. The majority of programs (master's, 73.1\%, $\mathrm{n}=114$ ); doctoral, $68.8 \%, n=11$ ) required submission of an essay or personal statement.

Occupational Therapist Centralized Application Service (OTCAS). As of July 2017, the majority of programs (master's, $60.9 \%, n=95$; doctoral, $100 \%, n=16$ ) required applicants to submit applications through the OTCAS. 
GRE. The majority of programs (master's, $53.9 \%, n=84$; doctoral, $68.8 \%, n=11$ ) required submission of GRE scores.

Interview. The majority of programs (master's, $50 \%, \mathrm{n}=78$; doctoral, $62.5 \%, \mathrm{n}=10$ ) required interviews as a component of the admission process. Details of personal interviews were rarely provided on program websites.

\section{DISCUSSION}

This paper describes recent admission requirements and practices that can provide helpful information as programs reflect on past, current, and future admission standards. Study findings provide information about admission requirements for occupational therapy programs that can be useful for the evaluation of admission criteria and processes. Although admission requirement information is available on each program's website, this study presents a comprehensive description of admission requirements for accredited entry-level occupational therapy programs in the United States. This information may be particularly useful as programs transition from entrylevel master's to entry-level doctoral programs. Findings gathered from the survey and website review present similar information. Overall, the results provided a synthesis of information about admission requirements as well as additional information that described programs' use of common cognitive (i.e., minimum P-GPA, GRE requirements) and non-cognitive (i.e., interview) admission requirements.

The majority of programs reported the use of P-GPA as an admission requirement. The use of P-GPA is well supported in the health profession literature (Halberstam \& Redstone, 2005; Kirchner et al., 2001; Kuncel, Hezlett, \& Ones, 2001; Lysaght et al., 2009; Siu \& Reiter, 2009). This study contributes additional information with the identification of average and range of minimum P-GPAs for 172 accredited entry-level master and doctoral programs.

This study found that $47 \%$ of survey respondents used at least one GRE score to make admission decisions; however, specific sub-test and average scores were not obtained. Results of the website review indicate more than $50 \%$ of programs require GRE scores (i.e., master's, 53\%; doctoral, 69\%). GRE scores have less published evidence to support usefulness as an admission requirement for health professions. Verbal GRE scores were shown to predict certification examination scores (Hollman et al., 2005); another study found a relationship between written GRE scores and student academic and clinical performance (Haber et al., 2015). The main reason cited by programs for not using GRE scores as an admission requirement was its inability to predict future academic and clinical performance (Cahn, 2014). Although not the focus of this study, the evidence that requiring the GRE may decrease the diversity of health profession programs' applicant pools also lends gravitas to the need for additional research regarding the predictive nature of this admission factor (Wolf, 2014). Future research about the use of specific sub-tests and sub-test scores, along with research related to program diversity, may better discern the value of the GRE in the admission process. 
With regard to non-cognitive admission factors, the results of both the survey $(67 \%$, $\mathrm{n}=30)$ and website review $(52 \%, \mathrm{n}=172)$ showed that the majority of programs use interviews as part of the admission process, despite the paucity of evidence to support the predictive value of an interview. Interviews are often cited as a means to measure non-cognitive variables, but this has not been supported through empirical data with allied health professions (Grapczynski \& Beasley, 2013; Lyons et al., 2006). The prevalence of interviews and other non-cognitive factors within the admission process may demonstrate programs' desire to consider a more holistic view of a prospective student than P-GPA or GRE scores can provide.

The majority of published studies examine outcomes related to the use of admission interviews in health professions (e.g., Goho \& Blackman, 2006; Li, Wilbarger, \& St. Louis, 2015; Lysaght et al., 2009; Pau et al., 2013). This study contributes additional information about the interview processes with regard to format and resources (i.e., time and personnel) for 20 occupational therapy programs in the United States. Responding programs reported high costs in terms of time spent by faculty and staff. This is consistent with other studies that report high costs to faculty, staff, and applicants for admission interviews (Gabard, Porzio, Oxford, \& Braun, 1997; Grice, 2014; Hazut, Romem, Malkin, \& Livshiz-Riven, 2016).

Survey respondents reported four main types of interview formats, with individual interviews with multiple interviewers as the most common. All interview formats reported by programs in the survey have been described in the literature as methods to measure applicants' non-cognitive skills, with the exception of a relatively new interview format, the multiple mini-interview (MMI) (Auriemma, 2007; Eva et al., 2004; Gabard et al., 1997; Grice, 2014). This survey revealed that $20 \%$ of respondents who conducted interviews used MMI. Occupational therapy programs in the process of examining admission criteria may consider reviewing additional research about MMI (e.g., Eva et al., 2004; Grice, 2014) and other emerging admission trends when considering methods to measure non-cognitive variables in the admission process.

The final purpose of this study was to examine the relationship between admission requirements and attrition. This study did not find any significant relationship between attrition and any admission criterion but did find a correlation between attrition and increased class size. Overall, occupational therapy programs have high retention rates (AOTA, 2015). Despite low attrition rates, the periodic study of admission factors in relation to attrition is warranted due to the large resource allotment (e.g., time, finances) by both programs and students (Eva et al., 2004). These findings suggest that increased attrition may occur with the admission of larger cohorts. Additional studies are necessary to support these findings.

\section{Limitations}

As with most survey methods, there are limitations to the study. The results of this descriptive study may not be representative of all entry-level occupational therapy programs due to the small return rate $(20 \%)$ despite multiple follow-up emails. Most respondents (38.7\%) were reporting on programs in the Midwest; nationally, only $25 \%$ 
of master's level programs in the United States are located in this region (AOTA, 2015). The time required to gather information to complete the survey may have contributed to the low response rate.

Researchers collected information from the survey and the website review within a two year time period. Although the survey findings (completed in 2015) about admission requirements were similar to those identified through website review (completed in 2017), the published admission information was limited to minimum admission requirements.

The survey did not provide information from doctoral level programs. All respondents were from master's level programs. However, this is not surprising as approximately $97 \%$ of all occupational therapy programs prepared students at the master's level at the time of the survey (AOTA, 2015).

Lastly, it was apparent respondents interpreted survey questions differently than intended, e.g. GRE sub-types. Descriptive information about GRE specific overall and subtests scores was limited due to inconsistencies related to the transition of GRE scoring methods during the time of the survey (Educational Testing Service, 2016). Similarly, attrition was reported as a categorical item (yes/no) rather than the number of occurrences. It is recommended that future studies specify GRE scores and attrition numbers to strengthen the statistical analysis for these items.

\section{CONCLUSION}

In this study, information on 31 entry-level, master's degree occupational therapy programs is presented to provide a detailed look at current admission practices in a small sample of programs in the United States. A website review provides an overview of national admission requirements. AOTA reports information on programs but does not report specific admission requirements for each program. Overall, the results of this study demonstrate the range of admission factors used by entry-level occupational therapy programs across the United States. Based on low national attrition rates (AOTA, 2015), programs are mostly successful at choosing students to meet the rigor of educational programs. Collaboration and increased communication between academic programs will allow for improved knowledge of admission practices and outcomes to maintain high retention rates and overall high quality of occupational therapy graduates entering the workforce as the profession shifts to doctoral entry-level education. Additionally, a study that includes more academic programs would provide a more representative sample of current admission requirements and practices. A longitudinal study to investigate the success of multiple cohorts may be necessary for further study into the predictive nature of admission criteria and processes with academic and clinical success.

\section{IMPLICATIONS FOR OCCUPATIONAL THERAPY EDUCATION}

Occupational therapy education programs admit approximately $17 \%$ of all applicants each year (AOTA, 2015). This robust applicant pool provides opportunity, responsibility, and challenges. Educational programs have a responsibility to society and the 
profession to select applicants who are well suited to meet the demands of occupational therapy programs and professional practice. The selection of applicants is complicated by a lack of empirical evidence with regard to predictive cognitive and non-cognitive admission factors, as well as a high cost in time and personnel resources for certain admission practices.

ACOTE and the AOTA's Commission on Education provide annual reports of admission data but do not report on specific admission requirements for each program. A synthesis of information about admission requirements and specific practices is valuable to occupational therapy education programs. The authors are faculty of two different occupational therapy education programs whose study involvement informed the reevaluation of some admission processes. Since then, both programs have implemented changes to admission practices. Periodic examination of admission processes within and across occupational therapy education program is important for the integrity of the profession (e.g., Auriemma, 2007).

\section{References}

American Occupational Therapy Association. (2017). ACOTE 2027 Mandate and FAQs. Retrieved from www.aota.org/Education-Careers/Accreditation/acote-doctoralmandate-2027.aspx

American Occupational Therapy Association. (2016). A descriptive review of occupational therapy education. American Journal of Occupational Therapy, 70, 7012410040. https://doi.org/10.5014/ajot.2016.706S03

American Occupational Therapy Association. (2015). Academic Programs Annual Data Report: Academic Year 2014-2015. Retrieved from http://www.aota.org/ /media/Corporate/Files/EducationCareers/Educators/20142015-Annual-Data-Report.pdf

American Occupational Therapy Association, (2007). A descriptive review of occupational therapy education. American Journal of Occupational Therapy, 61, 672-677. https://doi.org/10.5014/ajot.61.6.672

American Occupational Therapy Association. (n.d.). Find a School. Retrieved from https://www.aota.org/Education-Careers/Find-School.aspx

Auriemma, D. (2007). Admission methods of professional occupational therapy programs in the United States: 2001-2002. Education Special Interest Section Quarterly, 17(1), 1-3.

Baggs, T., Barnett, D., \& McCullough, K. (2015). The value of traditional cognitive variables for predicting performance in graduate speech-language pathology programs. Journal of Allied Health, 44(1), 10-16.

Cahn, P.S. (2014). Do health professions graduate programs increase diversity by not requiring the graduate record examination for admission? Journal of Allied Health, 44(1), 51-56.

Dahlin, M., Söderberg, S., Holm, U., Nilsson, I., \& Farnebo, L. (2012). Comparison of communication skills between medical students admitted after interviews or on academic merits. BMC Medical Education, 12(46). https://doi.org/10.1186/1472-6920-12-46 
Educational Testing Service. (2016). Scores. Retrieved from https://www.ets.org/gre/revised general/scores/

Eva, K.W., Rosenfeld, J., Reiter, H.I., \& Norman, G.R. (2004). An admissions OSCE: The multiple mini-interview. Medical Education, 38, 314-26. https://doi.org/10.1046/j.1365-2923.2004.01776.x

Fisher, G.S. (2000). The status of occupational therapy education in the 90's. Occupational Therapy in Health Care, 12(1), 1-15. https://doi.org/10.1080/J003v12n01 01

Gabard, D.L., Porzio, R., Oxford, T., \& Braun, R. (1997). Admission interviews: Questions of utility and cost in masters of physical therapy programs in the United States. Physiotherapy Research International, 2(3), 135-149. https://doi.org/10.1002/pri.96

Goho, J. \& Blackman, A. (2006). The effectiveness of academic admission interviews: An exploratory meta-analysis. Medical Teacher, 28(4), 335-340. https://doi.org/10.1080/01421590600603418

Grapczynski, C.A., \& Beasley, J. (2013). Occupational therapy admission: Professionalization and personality. Journal of Allied Health, 42(2), 112-119.

Grice, K.O. (2014). Use of multiple mini-interviews for occupational therapy admissions. Journal of Allied Health, 43(1), 57-61.

Haber, A., Fen, A., Perrine, K., Jin, J., Bathje, M., Ozelie, R. (2015) Relationship of undergraduate grade point average (GPA) and Graduate Record Examination scores with Level II fieldwork performance. American Journal of Occupational Therapy, 69 (Supplement_1), 6911505120p1. https://doi.org/10.5014/ajot.2015.69S1-PO5035

Halberstam, B., \& Redstone, F. (2005). The predictive value of admissions materials on objective and subjective measures of graduate school performance in speechlanguage pathology. Journal of Higher Education Policy and Management, 27(2), 261-272. https://doi.org/10.1080/13600800500120183

Hazut, K., Romem, P., Malkin, S., \& Livshiz-Riven, I. (2016). Computerized test versus personal interview as admission methods for graduate nursing studies: A retrospective cohort study. Nursing and Health Sciences, 18, 503-509. https://doi.org/10.1111/nhs.12309

Hollman, J.H., Rindflesch, A.B., Youdas, J.W., Krause, D.A., Hellyer, N.J., \& Kinlaw, D. (2008). Retrospective analysis of the behavioral interview and other preadmission variables to predict licensure examination outcomes in physical therapy. Journal of Allied Health, 37(2), 97-104.

IBM Corp. Released 2013. IMB SPSS Statistics for Windows, version 22.0. Armonk, NY: IBM Corp.

Kim, T., Change, J.Y., Myung, S.J., Chang, Y., Park, K.D., Park, W.B., \& Shin, C.S. (2016). Predictors of undergraduate and postgraduate clinical performance: A longitudinal cohort study. Journal of Surgical Education, 73(4), 715-720. https://doi.org/10.1016/j.jsurg.2016.03.006

Kirchner, G. L., Stone, R. G., \& Holm, M. B. (2001). Use of admission criteria to predict performance of students in an entry-level master's program on fieldwork placements and in academic courses. Occupational Therapy in Health Care, 13(1), 1-10. https://doi.org/10.1080/J003v13n01 01 
Kreiter, C.D., \& Kreiter, Y. (2007). A validity generalization perspective on the ability of undergraduate GPA and the medical college admission test to predict important outcomes. Teaching and Learning in Medicine, 19(2), 95-100. https://doi.org/10.1080/10401330701332094

Kuncel, N.R., Hezlett, S.A., \& Ones, D.S. (2001). A comprehensive meta-analysis of the predictive validity of the graduate record examinations: Implications for graduate student selection and performance. Psychological Bulletin, 127(1), 162-181. https://doi.org/10.1037/0033-2909.127.1.162

Li, K., Wilbarger, J., \& St. Louis, S. (2017). An innovative behavioral interview for preadmission selection of occupational therapy students. Journal of Occupational Therapy Education, 1(1). https://doi.org/10.26681/jote.2017.010107

Lyons, M., Mackenzie, L., Bore, M., \& Powis, D. (2006). Framing a set of non-academic selection criteria for occupational therapy students: An Australian study. Australian Occupational Therapy Journal, 53(4), 284-292. https://doi.org/10.1111/j.1440-1630.2006.00591.x

Lysaght, R., Donnelly, C., \& Villeneuve, M. (2009). Factors predicting applicant outcomes in occupational therapy education. Canadian Journal of Occupational Therapy, 76(1), 38-47. https://doi.org/10.1177/000841740907600110

Pau, A., Jeevaratnam, K., Chen, Y.S., Fall, A.A., Khoo, C., \& Nadarajah, V.D. (2013). The multiple mini-interview (MMI) for student selection in health professions training - A systematic review. Medical Teacher, 35(12), 10271041. https://doi.org/10.3109/0142159X.2013.829912

Siu, E., \& Reiter, H.I. (2009). Overview: What's worked and what hasn't as a guide towards predictive admissions tool development. Advances in Health Sciences Education, 14, 759-775. https://doi.org/10.1007/s10459-009-9160-8

SurveyMonkey [Computer software]. (n.d.). San Mateo, California: SurveyMonkey, Inc. Retrieved from www.surveymonkey.com

Utzman, R.R., Riddle, D.L., \& Jewell, D.V. (2007). Use of demographic and quantitative admissions data to predict academic difficulty among professional physical therapist students. Physical Therapy, 87(9), 1164-1180. https://doi.org/10.2522/ptj.20060221

Wolf, C. (2014). The effect of the graduate record examination on minority applications: Experience at New York Institute of Technology. Journal of Allied Health, 43(4), e65-7. 